\title{
Effects of Aspirin-Like Drugs on Mitogen- Stimulated DNA Synthesis of Lymphocytes from Pregnant Rats and Offspring
}

\author{
RICHARD M. MILLIS, MICHAEL C. EWII, GODWIN U. OFFIAH, BARBARA P. HYDE, AND \\ ENID M. KNIGHT \\ Animal Physiology Laboratory, Department of Zoology, Graduate School of Arts and Sciences and Department \\ of Human Nutrition and Food, School of Human Ecology, Howard University, Washington, D.C. 20059
}

\begin{abstract}
Previous studies have shown that salicylates and protein-calorie malnutrition compromise immunological responses in humans and experimental animals. The present study compared the effects of prenatal normal and low protein diets, with and without aspirin-like drug treatments, on lymphocyte blastogenesis measured by tritiated thymidine uptake for DNA synthesis in splenic lymphocytes from pregnant rats and their offspring following stimulation with the mitogens concanavalin $A$, phytohemagglutinin, and pokeweed mitogen. Aspirin treatment was associated with increased lymphocyte thymidine uptake for blastogenesis in pregnant rats fed the normal protein control diet and their offspring. The phytohemagglutinin-stimulated increase detected in offspring lymphocytes could not be statistically guaranteed. A low protein diet alone and a normal protein diet combined with salicylamide treatment was associated with decreased blastogenesis in pregnant rats but not in their offspring. Salicylamide or aspirin combined with a low-protein diet decreased blastogenesis in both dams and their offspring. Aspirin combined with a normal protein diet did not adversely affect blastogenesis in either pregnant rats or their offspring. This study suggests that low dietary protein and aspirin-like drugs may independently decrease lymphocyte blastogenesis of pregnant rats and in combination they may also reduce lymphocyte blastogenesis in offspring. The significance of increased lymphocyte blastogenesis in both mothers and offspring following aspirin treatment of pregnant rats fed a normal protein diet is unclear. (Pediatr Res 23: 93-97, 1988)
\end{abstract}

Abbreviations

PHA, phytohemagglutinin

PWM, pokeweed mitogen

Con A, concanavalin A

RDA, Recommended Dietary Allowance

HBSS, Hanks' balanced salt solution

MASH, Multiple Automated Sample Harvester

SPSS, Statistical Package for the Social Sciences

The results of in vitro studies on the effect of aspirin have led some researchers to assume that aspirin ingestion leads to in vivo

Received December 22, 1986; accepted September 22, 1987. Correspondence and requests for reprints Richard M. Millis, Ph.D., Assistant Professor, The American University, 4400 Massachusetts Avenue N.W., Biology Department/ Hurst Hall 101, Washington, D.C. 20016 suppression of human lymphocytes (1-4). However, results of in vivo studies of salicylates (aspirin) and suppression of lymphocyte transformation have been very conflicting.

Crout $e t$ al. (5) found marked suppression of blastogenesis in lymphocyte transformation studies using PHA and PWM on blood samples obtained from normal volunteers taking three aspirin tablets (totaling $900 \mathrm{mg}$ ) five times daily for 4 days (therapeutic dosage).

On the other hand, studies by Smith et al. (6) have shown that when 12 healthy subjects were placed on a dose of $600 \mathrm{mg}$ aspirin five times/day for 14 days, the capability of their lymphocytes to incorporate $\left[{ }^{3} \mathrm{H}\right]$ thymidine in response to PHA and allogenic lymphocytes was not statistically different from that of nontreated control subjects. The authors concluded that, within a $2-$ wk period, aspirin administered orally at therapeutic doses does not suppress lymphocyte responsiveness to either PHA or allogenic lymphocytes. Egorin et al. (7) obtained similar results in treating human subjects with 600 or $900 \mathrm{mg}$ aspirin four times daily for $1 \mathrm{wk}$. They found that when taken orally, salicylate did not induce any irreversible change in the capability of lymphocytes to respond to isolectin stimulation.

Although these results on lymphocyte reaction to mitogens are conflicting, the possibility remains that treatment with aspirinlike drugs at a reduced dietary protein level might decrease the immunocompetence of pregnant mothers and their offspring. When used in pregnancy above pharmacological levels, aspirinlike drugs might therefore pose a risk to the fetus of mothers with poor nutritional status.

Previous studies have shown that maternal protein restriction in rats retards placental and fetal growth (8). The importance of maternal dietary protein to human fetal growth and development has been recently underscored by directive of the U.S. Food and Drug Administration to increase the RDA of protein for pregnant mothers. Offspring of mothers who ingest salicylates chronically have had significantly reduced birth weights and increased perinatal mortality (9). The negative nitrogen balance, uncoupling of oxidative phosphorylation, and adrenocortical activation associated with salicylate treatment (10) might produce conditions unfavorable to lymphocyte proliferation and antibody production.

The purpose of this study is to examine the interaction effect of a protein-deficient diet and aspirin-like drug ingestion during pregnancy on maternal and offspring lymphocyte transformation in response to the mitogens PHA, PWM, and Con A.

\section{METHODS}

Experiment I. Animals. One hundred twenty pregnant Sprague-Dawley rats 3 to 4 months old were used in this study. Nonpregnant weights ranged from 200 to $300 \mathrm{~g}$ prior to distri- 
bution to cages. They were bred with normal male rats at the Howard University Animal Resources Facility in Beltsville, MD.

Diets and Food Intake. Rats were divided into six weightmatched groups of 20 rats each. Table 1 summarizes the dietary treatments of control and experimental groups. To determine the effects of aspirin-like drugs on an important determinant of immune responses of pregnant rats and their offspring, experimental groups of pregnant rats were fed either aspirin or salicylamide. Animals were fed ad libitum from day 1 of gestation through delivery (days 19-21). Weight gain and food intake were recorded twice weekly.

After delivery, five pups from each group were culled to each dam, and a total of 10 dams from each group was used for weaning. The remaining 10 dams from each group were sacrificed by cervical dislocation and serum from blood samples was collected and frozen for subsequent analysis.

Mitogenic Response of Splenic Lymphocytes. Each spleen was removed with sterile scissors and forceps, weighed, and transferred to $10 \mathrm{ml}$ of cold $\left(5^{\circ} \mathrm{C}\right) \mathrm{HBSS}$ (Biofluid Inc., Rockville, MD), which was later transferred to a sterile glass Petri dish for cell suspension preparation.

Suspensions were washed twice by centrifugation with $10 \mathrm{cc}$ HBSS at $1500 \mathrm{rpm}$ for $10 \mathrm{~min}$ at $5^{\circ} \mathrm{C}$ in a refrigerated centrifuge. The resulting pellet was suspended in $2 \mathrm{ml}$ of cold culture media consisting of $91 \%$ RPMI media, $4 \%$ antibiotic $(250,000 \mathrm{U}$ penicillin/streptomycin), and $5 \%$ fetal calf serum.

Acetic acid (3\%) was used to lyse erythrocytes and the suspension was transferred to a white cell hemocytometer for counting. The entire cell suspension was diluted to $5 \times 10^{6}$ cells $/ \mathrm{ml}$ of culture media. From this dilution, $5 \times 10^{5}$ cells in $0.1 \mathrm{ml}$ were cultured in triplicate in microtiter culture dishes with either PHA $0.313 \mu \mathrm{g}$ in $0.1 \mathrm{ml}$; Con A $2.5 \mu \mathrm{g}$ in $0.1 \mathrm{ml}$; and PWM in a ratio of $1: 20 \mu \mathrm{g}$ in $0.1 \mathrm{ml}$. Control wells with unstimulated cells contained $5 \times 10^{6}$ cells in $0.1 \mathrm{ml}$ culture medium.

The cells were incubated for $72 \mathrm{~h}$ in $5 \% \mathrm{CO}_{2}$ atmosphere at $37^{\circ} \mathrm{C}$. Five $\mathrm{h}$ prior to the termination of incubation, each well was labeled with $1.0 \mu \mathrm{Ci}\left[{ }^{3} \mathrm{H}\right]$ thymidine (New England Nuclear, Boston, MA) and reincubated under the same conditions. At the end of the incubation period, the cells were harvested via a MASH (Microbiological Associates, Walkersville, MD) onto MASH II glass fiber filters and allowed to dry overnight.

The following day, each section of the filter was individually placed in $5 \mathrm{ml}$ of liquid scintillation cocktail consisting of $0.1 \%$ of 1,4-bis-2-5-phenyloxazolylbenzene scintillation grade and $5 \%$ 2,5-diphenyloxazole scintillation grade in counting vials and allowed to stand in the dark for $30 \mathrm{~min}$, after which the samples were placed in a liquid scintillation counter. Results obtained after counting were expressed in counts per minute (cpm).

Experiment II. This study was designed to determine if treatment of the dams affected the offspring, specifically to determine whether salicylamide, aspirin, or dietary protein affects the immune system of the offspring.

Animals. Sixty male and female Sprague-Dawley weanling rats, age $3 \mathrm{wk}$, were used. Their weights ranged from 24 to $60 \mathrm{~g}$ prior to distribution to cages. They were divided into six groups of 20 rats each, corresponding to the groups in experiment $\mathrm{I}$, i.e. offspring from experiment I, group 1 were designated as group 7 in experiment II, etc. (Table 1).

Each group in experiment II was fed a normal control diet of $25 \%$ protein ad libitum for 60 days. Weight gain was recorded once a week. At the end of day 60 , animals were sacrificed and the methods and procedures performed during experiment I were followed.

Statistical significance of differences between control and experimental groups was guaranteed by Duncan's multiple range test computed electronically by the SPSS software program on an IBM 270 computer.

\section{RESULTS}

Effects of aspirin on Con A-stimulated lymphocytes. Aspirin treatment of pregnant rats fed the normal protein control diet (group 2) was associated with increased amounts of radioactive thymidine incorporated into DNA within lymphocytes stimulated by the mitogen Con A; aspirin treatment of pregnant rats fed the low protein diet (group 5) was associated with additional decreases in thymidine uptake compared to animals on the normal protein diet both with (group 2) and without aspirin treatment (group 1) (Fig. 1).

Similarly, Con A-stimulated lymphocytes from offspring of dams fed aspirin with the normal protein control diet exhibited greater blast transformation than lymphocytes from offspring of dams fed the normal protein diet without aspirin. Lymphocytes from the offspring of dams fed aspirin with the low-protein diet showed significantly less blastogenesis than lymphocytes from offspring of dams fed aspirin with the normal protein diet and less blastogenesis than lymphocytes from offspring of dams fed the low protein diet without aspirin (Fig. 1).

Effects of aspirin on PHA-stimulated lymphocytes. When stimulated by PHA, lymphocytes from pregnant dams treated with aspirin and fed both the normal and the low protein diet (groups 2 and 5) exhibited significantly greater blast transformation than lymphocytes from pregnant dams fed the normal protein diet without aspirin treatment (group 1) (Fig. 2). PHA-stimulated blast transformation of lymphocytes from dams fed the lowprotein diet with aspirin (group 5) was greater than that of dams fed the low protein diet without aspirin treatment (group 4).

PHA-stimulated lymphocytes from offspring showed no blastogenic effects following maternal aspirin treatment under either normal or low protein dietary conditions (Fig. 2).

Effects of aspirin on PWM-stimulated lymphocytes. PWMstimulated lymphocytes from pregnant rats exhibited greater blast transformation when normal dietary protein with aspirin (group 2) was compared to normal dietary protein conditions without aspirin treatment (group 1) (Fig. 3).

PWM-stimulated blast transformation of lymphocytes from pregnant rats treated with aspirin and fed a low protein diet (group 5) was significantly less than that from pregnant rats fed the normal protein diet with aspirin treatment (group 2), but transformation of lymphocytes from group 5 rats fed the low protein diet combined with aspirin was greater than that from pregnant rats fed the low protein diet without aspirin (group 4).

Table 1. Dietary treatment of groups

\begin{tabular}{ccccc}
\hline Group & Experiment I & Experiment II & Dietary protein $(\%)$ & Drug \\
\hline Normal protein & 1 & & & 25 \\
Control & 2 & 7 & 25 & $0.25 \%$ aspirin \\
Experimental & 3 & 8 & 25 & $1 \%$ salicylamide \\
Experimental & & 9 & & \\
Low protein & 4 & 10 & 8 & $0.25 \%$ aspirin \\
Control & 5 & 11 & 8 & $1 \%$ salicylamide \\
Experimental & 6 & 12 & & \\
Experimental & & & & \\
\hline
\end{tabular}


Con A
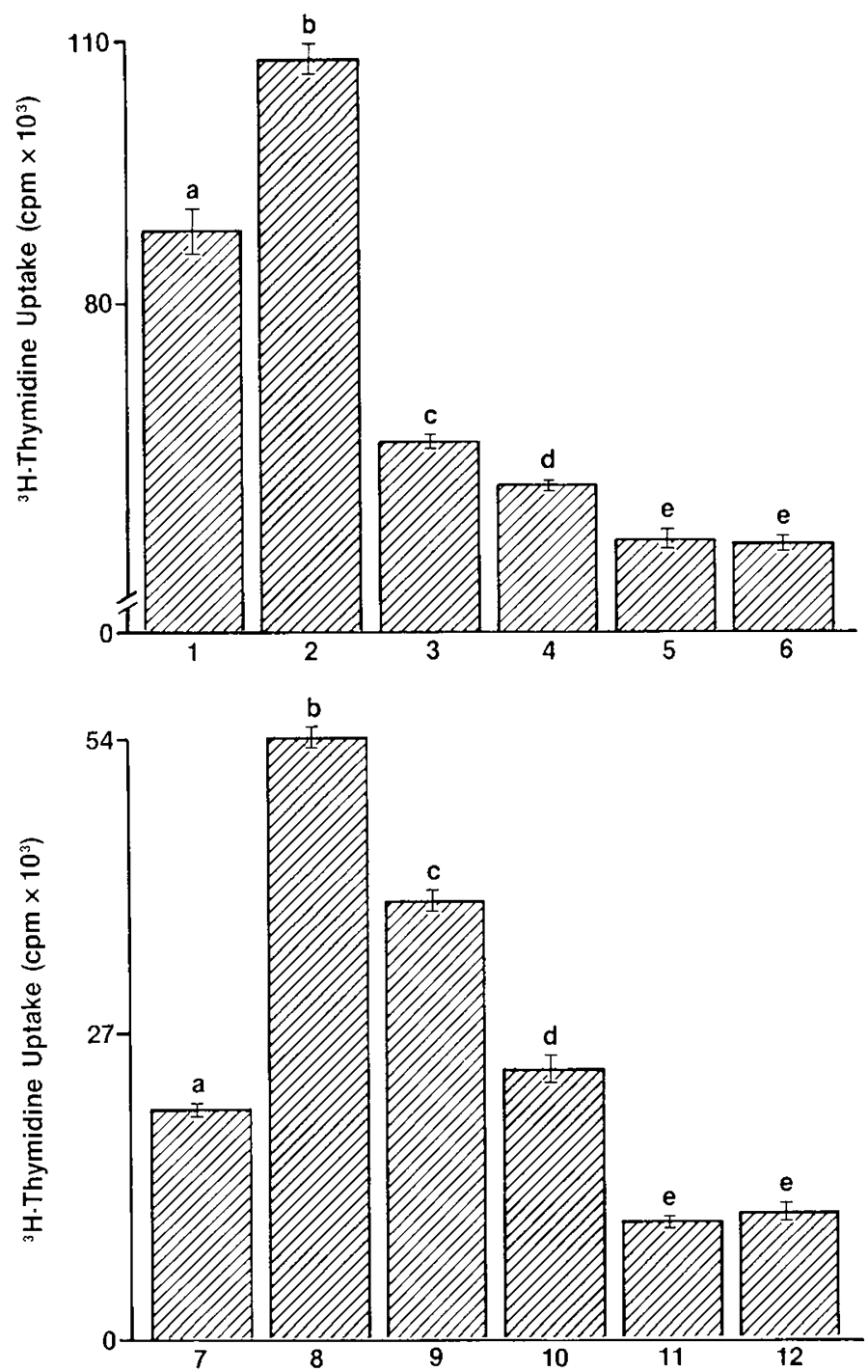

Fig. 1. Con A response of dams and offspring lymphocytes. Vertical bars show mean \pm SEM tritiated thymidine uptake $\left(\mathrm{cpm} \times 10^{3}\right)$ of splenic lymphocytes from pregnant rats (groups 1-6) and offspring (groups 7-12) following mitogenic stimulation with Con A. Group 1-6 (experiment I, Table 1) lymphocytes were taken from pregnant rats fed the following diets: 1 . normal $(25 \%)$ protein control; 2 . normal $(25 \%)$ protein with $0.25 \%$ aspirin added; 3 . normal $(25 \%)$ protein with $1 \%$ salicylamide added; 4 . low (8\%) protein control; 5. low (8\%) protein with $0.25 \%$ aspirin added; 6 . low $(8 \%)$ protein with $1 \%$ salicylamide added. Group 7-12 (experiment II, Table 1) lymphocytes were taken from offspring of the pregnant rats fed diets $1-6$, respectively. Offspring were 3 -wk-old weanlings fed the normal (25\%) protein control diet for 60 days. Equivalent letters above each bar indicate homogeneous subsets, differences between which were determined not to be statistically significant $(p>0.05)$; nonequivalent letters indicate heterogeneous subsets, differences between which were determined to be statistically significant $(p<0.05)$ by Duncan's analysis of variance. Values on ordinate expressed in $\mathrm{cpm} \times 10^{3}$.

However, blastogenesis in PWM-stimulated lymphocytes from group 5 pregnant rats fed the low protein diet with aspirin was not significantly different than that from pregnant rats fed the normal control diet without aspirin (group 1).

Figure 3 shows that PWM-stimulated lymphocytes from offspring of dams fed aspirin with both the normal protein diet (group 8) and the low protein diet (group 11) exhibited greater blastogenesis than lymphocytes from the offspring of dams fed

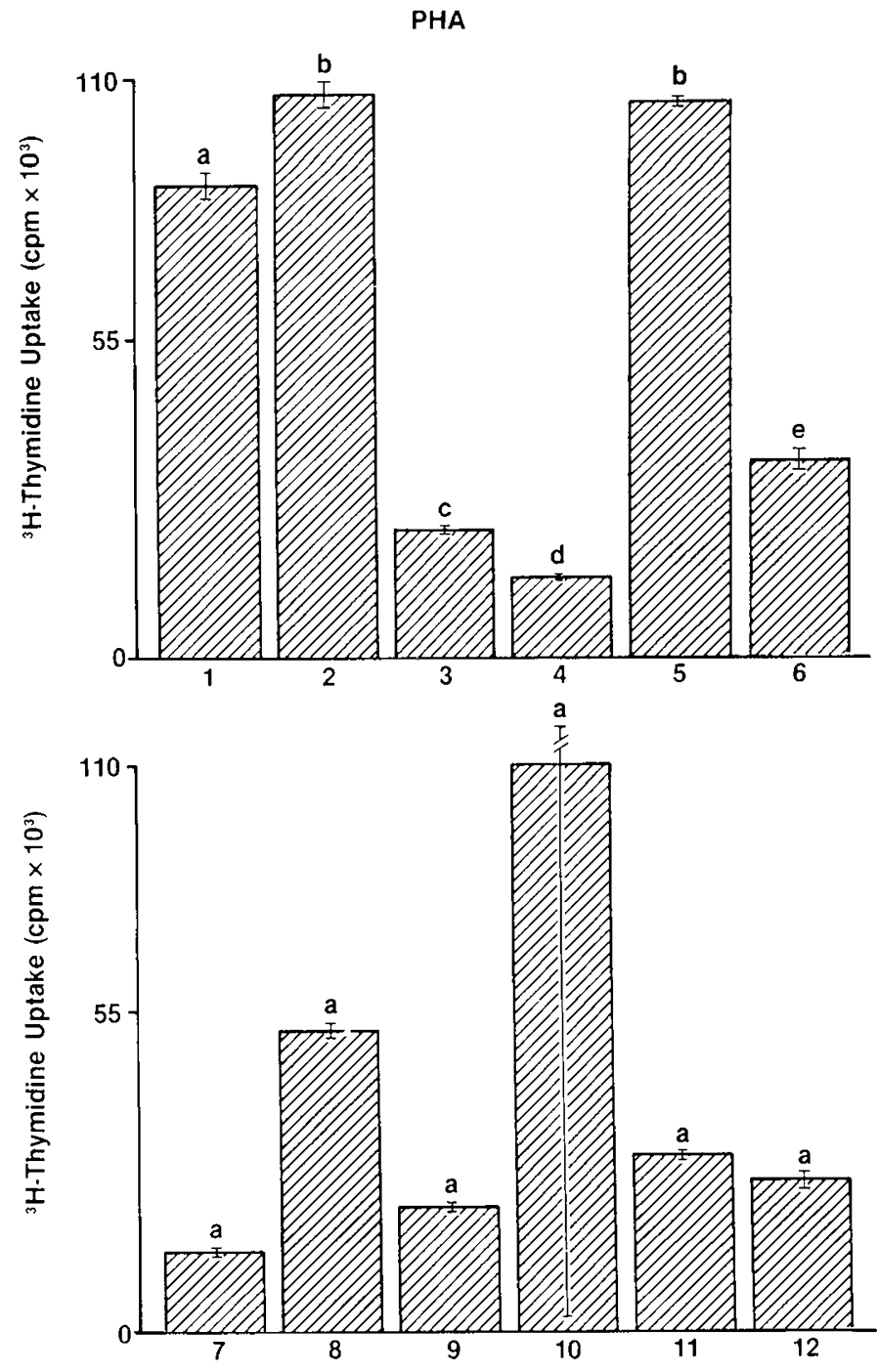

Fig. 2. Phytohemagglutinin response of dams and offspring lymphocytes. Vertical bars show mean \pm SEM tritiated thymidine uptake (cpm $\times 10^{3}$ ) of splenic lymphocytes from pregnant rats (groups 1-6) and offspring (groups 7-12) following mitogenic stimulation with PHA. Group 1-6 (experiment I, Table 1) lymphocytes were taken from pregnant rats fed the following diets: 1 . normal $(25 \%)$ protein control; 2. normal $(25 \%)$ protein with $0.25 \%$ aspirin added; 3 . normal $(25 \%)$ protein with $1 \%$ salicylamide added; 4 . low $(8 \%)$ protein control; 5 . low $(8 \%)$ protein with $0.25 \%$ aspirin added; 6 . low (8\%) protein with $1 \%$ salicylamide added. Group 7-12 (experiment II, Table 1) lymphocytes were taken from offspring of the pregnant rats fed diets 1-6, respectively. Offspring were 3 -wk-old weanlings fed the normal $(25 \%)$ protein control diet for 60 days. Equivalent letters above each bar, indicate homogeneous subsets, differences between which were determined not to be statistically significant ( $p>0.05)$; nonequivalent letters indicate heterogeneous subsets, differences between which were determined to be statistically significant $(p<0.05)$ by Duncan's analysis of variance. Values on ordinate expressed in $\mathrm{cpm} \times 10^{3}$.

the normal protein control diet without aspirin (group 7). However, lymphocytes from group 11 offspring fed the low protein diet with aspirin showed less blast transformation than either those from group 8 offspring of dams fed aspirin with the normal protein diet or group 10 offspring from dams fed the low-protein diet without aspirin treatment.

Effects of salicylamide on Con A-stimulated lymphocytes. Splenic lymphocytes from pregnant rats fed the normal and lowprotein diets with salicylamide (groups 3 and 6) exhibited decreased blastogenesis following stimulation by Con A (Fig. 1). 

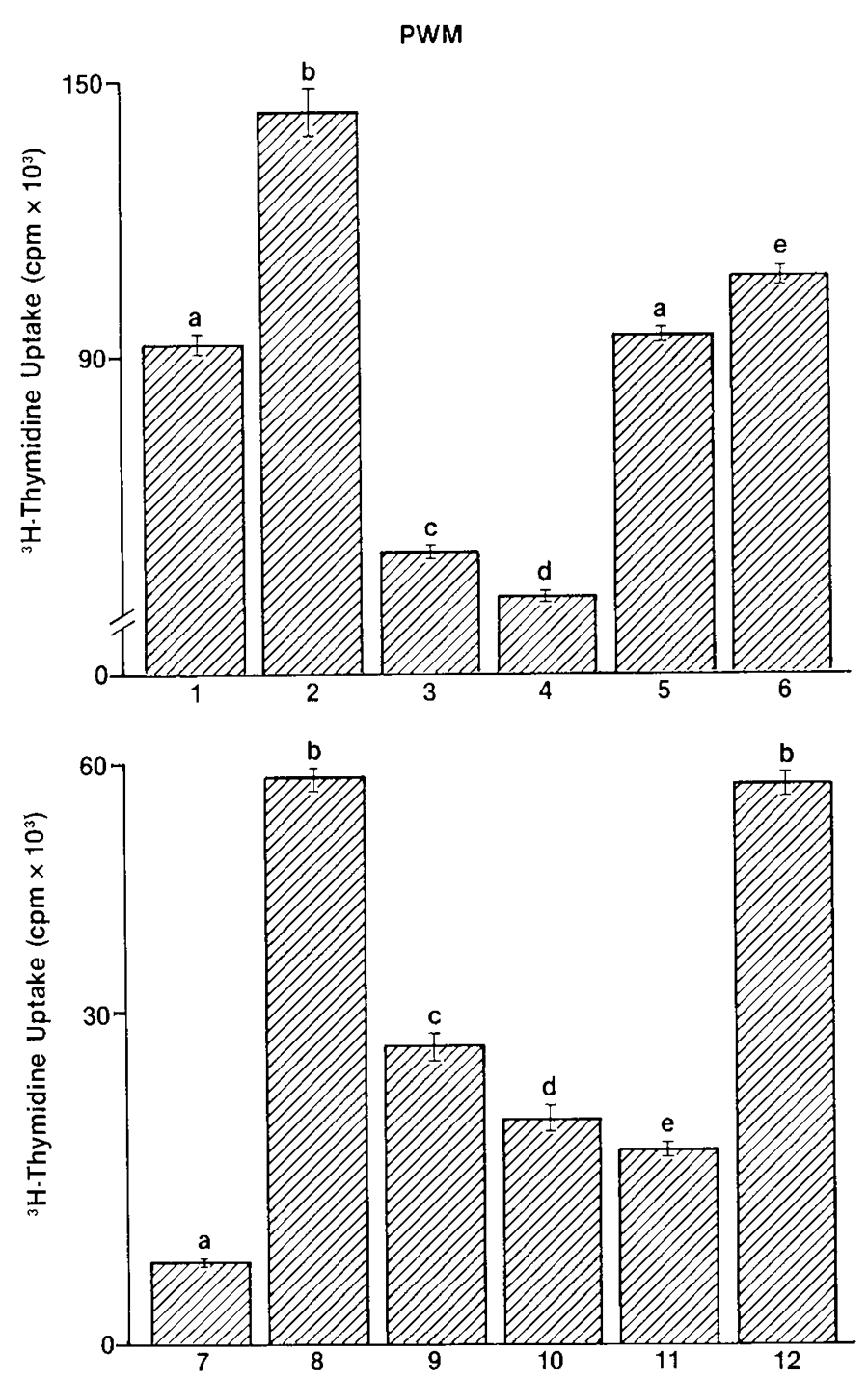

Fig. 3. PWM response of dams and offspring lymphocytes. Vertical bars show mean \pm SEM tritiated thymidine uptake $\left(\mathrm{cpm} \times 10^{3}\right)$ of splenic lymphocytes from pregnant rats (groups 1-6) and offspring (groups 7-12) following mitogenic stimulation with PWM. Group 1-6 (experiment I, Table 1) lymphocytes were taken from pregnant rats fed the following diets: 1 . normal $(25 \%)$ protein control; 2 . normal $(25 \%)$ protein with $0.25 \%$ aspirin added; 3 . normal $(25 \%)$ protein with $1 \%$ salicylamide added; 4 . low (8\%) protein control; 5 . low (8\%) protein with $0.25 \%$ aspirin added; 6 . low $(8 \%)$ protein with $1 \%$ salicylamide added. Group 7-12 (experiment II, Table 1) lymphocytes were taken from offspring of the pregnant rats fed diets $1-6$, respectively. Offspring were 3 -wk-old weanlings fed the normal $(25 \%)$ protein control diet for 60 days. Equivalent letters above each bar indicate homogeneous subsets, differences between which were determined not to be statistically significant $(p>0.05$ ); nonequivalent letters indicate heterogenous subsets, differences between which were determined to be statistically significant $(p<0.05)$ by Duncan's analysis of variance. Values on ordinate expressed in $\mathrm{cpm} \times 10^{3}$.

Salicylamide treatment of pregnant rats fed the low-protein diet (group 6) was associated with significantly less Con A-stimulated lymphocyte blastogenesis than that in pregnant rats fed the low protein diet without salicylamide treatment (group 4).

Increased Con A-stimulated lymphocyte blastogenesis was detected in lymphocytes from offspring of dams fed the normal protein diet with salicylamide. Low dietary protein with salicylamide treatment of dams was associated with decreased Con Astimulated blastogenesis in offspring compared to that in both offspring of dams fed the low-protein diet without salicylamide and offspring of dams fed the normal protein diet with salicylamide (Fig. 1).

Effects of salicylamide on PHA-stimulated lymphocytes. PHA stimulation of lymphocytes from pregnant rats fed the normal protein diet with salicylamide showed decreased blast transformation. Increased blastogenesis was detected in lymphocytes from dams fed the low protein as compared with the normal protein diet combined with salicylamide treatment. Salicylamide treatment of pregnant rats fed the low protein diet was associated with a lower level of PHA-stimulated blastogenesis than in pregnant rats fed the normal protein control diet without salicylamide, but with a higher level than in either those fed the normal protein diet with salicylamide or fed the low protein diet without salicylamide (Fig. 2).

Salicylamide had no effect on blast transformation of PHAstimulated lymphocytes from offspring of dams fed both normal and low protein diets (Fig. 2).

Effects of salicylamide on PWM-stimulated lymphocytes. Compared to controls (group 1), blastogenesis was lower in PWM-stimulated lymphocytes from pregnant rats fed the normal protein diet with salicylamide (group 3 ) but greater in those from dams fed the low-protein diet with salicylamide (group 6) (Fig. 3 ). Blastogenesis in the latter group 6 animals was even greater than that detected in PWM-stimulated lymphocytes from pregnant rats fed either the low protein diet without salicylamide (group 4) or the normal protein diet with salicylamide (groups 3 and 1).

Figure 3 shows that salicylamide treatments of dams fed both the low-protein and normal protein diets were associated with increased blastogenesis of PWM-stimulated lymphocytes from their offspring (groups 9 and 12) compared to that in lymphocytes from offspring of dams fed either the normal protein diet or the low-protein diet without salicylamide treatment (groups 7 and 10).

\section{DISCUSSION}

Acetylsalicylic acid (aspirin) is one of the most commonly used drugs because of its efficacy as an analgesic, antipyretic, and antiinflammatory agent, the low cost and relative safety. Although there is no evidence that therapeutic doses of salicylates cause fetal damage in humans, infants born to women who chronically ingest salicylates may have significantly decreased birth weights (10). The present studies suggest that maternal and neonatal effects on in vitro lymphocyte blastogenesis may be observed when chronic maternal ingestion of aspirin-like drugs is associated with protein-deficient diets. It is probable that the low protein maternal diet decreased the serum protein concentration that would have had the effect of decreasing the amount of aspirin-like drug bound to serum albumin and increasing the amount of unbound, pharmacologically active drug, relative to the control normal maternal dietary protein conditions. However, the extent to which variable concentrations of active aspirinlike drugs may have become incorporated into the in vitro lymphocyte blast transformation test system when applied to lymphocytes from pregnant rats under normal versus low protein conditions was not determined.

Numerous investigations have focused on the effects of aspirin on various aspects of cellular immunology. In vitro studies by several researchers have demonstrated that aspirin (salicylates) suppresses lymphocyte transformation (1-3). Aspirin added to cultures of normal lymphocytes inhibited blastogenic response of these cells to crude preparations of PHA $(1,2,4)$.

Crout et al. (5) reported a blastogenic response ratio after in vivo salicylate ingestion of 0.49 , compared with ratios of 0.25 (1) and $0.16(2)$ in cultures exposed simultaneously to PHA and salicylate in vitro. The authors concluded that oral administration of aspirin significantly suppresses lymphocyte transformation. Ganter and Zuckner (3) suggest that ingestion of a single therapeutic dose of aspirin by a normal person can completely inhibit 
in vitro lymphocyte transformation by PHA for periods of 25 to $36 \mathrm{~h}$.

Mitogen-stimulated splenic lymphocyte proliferation was uniformly decreased in pregnant rats fed the normal protein diet plus salicylamide and mimicked the effects of the low protein diet on the dams. Similarly, the effects of salicylamide and aspirin in the offspring of rats fed the normal protein diet mimicked the effects of low maternal dietary protein on the offspring of dams fed the normal protein diet; increased splenic lymphocyte blastogenesis resulted from activation by the mitogens Con $\mathrm{A}$ and PWM, with no effect seen in PHA-stimulated lymphocytes.

Mitogen-stimulated splenic lymphocyte proliferation was uniformly increased in pregnant rats fed the normal protein diet with aspirin treatment. These results suggest that aspirin treatment might increase cellular and humoral immunity in pregnant rats under normal dietary protein conditions, but these findings are in sharp contrast to the generally accepted result that in vivo aspirin treatment decreases in vitro mitogen-stimulated lymphocyte blastogenesis. Indeed, such conflicting results emphasize the problem of applying the significance of in vitro findings to in vivo cellular immune responsiveness.

The increase in PWM-stimulated lymphocyte blastogenesis associated with aspirin treatment of pregnant dams under normal dietary protein conditions might suggest a tendency toward increased tumorigenesis because of greater B cell mediated synthesis of blocking antibodies $(11,12)$. However, greater control of Walker neoplasm growth attributed to aspirin might actually result from synthesis of an antiosteolytic factor (13) and may therefore be unrelated to immune function per se.

A more recent report that enhancement of suppressor $\mathrm{T}$ cell activity was associated with decreased antibody secretion in response to blood lymphocyte activation by PWM (14) suggests that the combination of conditions that produces decreased PWM-stimulated lymphocyte proliferation associated with increased Con A-stimulated lymphocyte proliferation may provide a physiological experimental model for study of the human response to splenectomy (14).

In the present studies, decreased in vitro PWM-stimulated blast transformation of splenic lymphocytes was also associated with decreased in vitro responsiveness to Con A. This combination was observed in lymphocytes from pregnant rats under low dietary protein conditions, low dietary protein with aspirin treatment, normal dietary protein with salicylamide treatment, and from the offspring of dams fed a low-protein diet with aspirin treatment. Low dietary protein alone and in combination with salicylamide treatment of pregnant rats produced uniform decreases in in vitro $\mathrm{T}$ lymphocyte blastogenesis as evidenced by Con A and PHA activation studies.

Stephenson (15) reported that rats were more sensitive to aspirin-induced than salicylamide-induced thymic atrophy. The rationale for feeding these two aspirin-like drugs to pregnant rats at different dose levels has been provided by earlier studies demonstrating anorexia at dietary aspiring concentrations of more than $0.5 \%$, but up to $4 \%$ salicylamide was tolerated without significant effects on food intake (15). Because cell-mediated immunity is greatly dependent on macrophage function, studies of blood macrophages may provide some insight into the effects of aspirin on cell-mediated immune functions. Recent investigations have shown that aspirin pretreatment prevents the depression of function of blood macrophages associated with menses in women (16).

Such findings are similar to the enhancement of in vitro Con A and PWM activation of splenic lymphocytes that were associated with no effect on PHA activation in offspring of dams fed a low protein diet with and without treatment with the aspirinlike drugs, salicylate and salicylamide, in this study.

\section{SUMMARY AND CONCLUSIONS}

In pregnant dams, lymphocytes stimulated by Con A, PHA, and PWM exhibited increased blastogenesis in vitro in response to aspirin treatment combined with the normal protein diet; under low protein dietary conditions, increased in vitro blastogenesis was observed only in response to PHA stimulation. Only Con A-stimulated lymphocytes from pregnant dams exhibited very low levels of in vitro blastogenesis with aspirin treatment under low dietary protein conditions. Con A- and PWM-stimulated lymphocytes from offspring of dams fed the normal protein diet with aspirin showed increased in vitro blastogenesis that was not observed when lymphocytes were stimulated by PHA. In the offspring, decreased in vitro lymphocyte blastogenesis associated with aspirin treatment of dams was clearly detected only under Con A stimulation of lymphocytes from dams treated with low dietary protein condition during gestation.

Only Con A-stimulated lymphocytes exhibited uniformly decreased in vitro blastogenic responsiveness from both pregnant rats and their offspring as a result of treatment with salicylamide.

Because of the problems of equating in vitro with significant in vivo immunological deficiency, the statistically significant in vitro lymphocyte blastogenic effects described herein should be interpreted cautiously pending confirmation by tests of in vivo immune functions.

Acknowledgment. The authors acknowledge the assistance of Doris Hughes, D.V.M. who supervised breeding of animals used in this study at the Howard University Animal Resource Facility, Beltsville, MD.

\section{REFERENCES}

1. Opelz G, Terasaki PI 1973 Suppression of lymphocyte transformation by aspirin. Lancet 2:478-480

2. Pachman LM, Esterly NB, Peterson RD 1971 The effect of salicylate on the metabolism of normal and stimulated human lymphocytes in vitro. J Clin Invest 50:226-230

3. Ganter GE, Zuckner J 1965 Suppression of lymphocyte transformation. Arthritis Rheum 8:443

4. Schneider W, Pappas A, Scheurlen PG 1971 The effect of acetylsalicylic acid on the metabolism and transformability of human lymphocytes in vitro. Clin Wochschr 49:1187-1189

5. Crout JE, Hepburn B, Ritts RE 1975 Suppression of lymphocyte transformation after aspirin ingestion. N Engl J Med 292:221-233

6. Smith JW, Steiner AL, Parker GW 1971 Human lymphocyte metabolism: effects of cyclic and noncyclic nucleotides on stimulation by phytohemagglutinin. J Clin Invest 50:442-448

7. Egorin MJ, Felsted RL, Bachur NR 1978 Salicylate effects on the response of human lymphocytes to phytohemagglutinin isolectins. Clin Immunol Immunopathol 10:1-10

8. Chow BF, Lee CJ 1964 Effect of dietary restriction of pregnant rats on body weight gains of the offspring. J Nutr 82:10

9. Collins E 1981 Maternal and fetal effects of acetaminophen and salicylates in pregnancy. Obstet Gynecol 58:575-625

10. Flower RJ, Moncada S, Vane JR 1985 Analgesic-antipyretics and anti-inflammatory agents: drugs employed in the treatment of gout. In: Gilman AG, Goodman LS, Rall TW, Murad F (eds) The Pharmacological Basis of Therapeutics. Macmillan, New York, pp 674-715

11. Yutoko M, Kitagawa M 1975 The role of alloantibodies on in vivo growth of allografted tumor. Transplant Proc 7:105-108

12. Ting CC, Herberman RB 1975 Specific afferent interference by antiserum of in vivo immunity. Nature 257:801-802

13. Powles TJ, Clark SA, Easty DM, Easty GC, Neville AM 1973 The inhibition by aspirin and indomethacin of osteolytic tumor deposits and hypercalcaemia in rats with Walker tumor and its possible application to human breast cancer. Br J Cancer 28:316

14. Tauris $P 1983$ Plaque-forming cells in man. Evidence of the existence of active suppressor cells in peripheral blood of normal plaque-forming cell nonresponders. Scand J Immunol 18:249-253

15. Stephenson NR 1959 Effect of salicylates in the thymus gland of the immature rat. J Pharmacol 11:339-345

16. Berger EM, Harada RN, Vatter AE, Bowman MC, Repine JE 1984 Cyclical abnormalities in the bactericidal function, superoxide production, and lysozyme activity of neutrophils obtained from a healthy woman during menstruation: reversal by pretreatment with aspirin. J Infect Dis 149:413-419 


\section{Erratum}

Volume 22, Number 5, November 1987, pp. 616-620. Atriovenous Nodal Function in the Immature Canine Heart, by Jorge McCormack, Henry Geland, Hui Zu, Juan Villafane, Adrienne Stolfi, and Arthur S. Pickoff.

The above article is reprinted in its entirety on pages $99-103$ due to a printer's error. AV was incorrectly written out as 'atriovenous' rather than 'atrioventricular.' Both the printer and the publisher regret this error. 